\title{
Urban Traffic Network Sustainability of One-Way and Two- Way Streets: A Case Study in Downtown Brickfields, Kuala Lumpur
}

\author{
Y. H. Chow ${ }^{1}$, Q. Y. Tan ${ }^{1}$, M. A. S. Bhuiyan ${ }^{2}$, B. V. D. Kumar ${ }^{2}$, M. B. I. Reaz ${ }^{3}$, C. W. Yuen ${ }^{4,5}$, K. J. A. Ooi ${ }^{6, *}$ \\ ${ }^{1}$ School of Energy and Chemical Engineering, Xiamen University Malaysia, Sepang 43900, Malaysia. \\ ${ }^{2}$ School of Electrical and Computer Engineering, Xiamen University Malaysia, Sepang 43900, Malaysia. \\ ${ }^{3}$ Faculty of Engineering and Built Environment, Universiti Kebangsaan Malaysia, Bangi 43600, Malaysia. \\ ${ }^{4}$ Department of Civil Engineering, Faculty of Engineering, Universiti Malaya, Kuala Lumpur 50603, Malaysia. \\ ${ }^{5}$ Centre for Transportation Research, Universiti Malaya, Kuala Lumpur 50603, Malaysia. \\ ${ }^{6}$ Department of Physics, Xiamen University Malaysia, Sepang 43900, Malaysia. \\ *Correspondence: kelvin.ooi@xmu.edu.my
}

\begin{abstract}
The once-held wisdom of the supreme efficiency of one-way streets has been gradually supplanted by the perceived sustainability of two-way streets in the design of livable cities that prioritizes the safety of pedestrians and thriving of local businesses. However, it is rarely discussed on whether one-way street conversions have truly improved the long-term traffic efficiencies on urban street networks, as conflating socioeconomic factors such as vehicular population growth and induced travel demand may render empirical analysis inconclusive. In this study, microscopic traffic simulations implemented on SUMO platform was performed to analyze the effect of street conversion in Downtown Brickfields, Kuala Lumpur. This approach can control and standardize travel demand in both one-way and two-way street networks, and would therefore give a fairer evaluation by precluding all socioeconomic factors. It was found that one-way streets do not necessarily improve the traffic efficiency of the network, as it is very dependent on the traffic scenario evolution over time. One-way streets perform better at the onset of traffic congestion due to its higher capacity, but on average, the 4-fold longer travel times that made it harder to clear traffic by getting vehicles to their destinations compared to two-way streets. As time progresses, congestion in one-way streets may become twice as worse compared to two-way streets. This study may contribute to a more holistic assessment of traffic circulation plan designed for smart and livable cities.
\end{abstract}

Keywords: street conversion; urban traffic network; traffic simulation

\section{Introduction}

Traffic assignment has been an integral part of urban planning ever since the proliferation of motorized vehicles from the 1950s. Prediction of travel demand and then planning the suitable street configuration is necessary to ensure smooth traffic flow and relieve congestion. One of the aspects of street configuration is the traffic circulation plan that governs street directionality. In the past, traffic flow had always been presumed to be bidirectional, and drivers only needed to adhere to either the left-hand or right-hand traffic rule to avoid collision with the opposing traffic. As the number of vehicles increased over the years which heightened the stress of traffic densities in urban streets, traffic planners redesigned traffic circulation plans by implementing additional street rules, one of them being the conversion of two-way streets into one-way streets. A famous historical anecdote would be Albemarle Street in London, where conversion into a one-way traffic was made due to severe traffic congestion caused by people travelling to attend Humphry Davy's lectures at the Royal Institution. Since then, it seemed to be common wisdom to traffic engineers that one-way streets are superior to two-way streets from the argument of driver safety, traffic capacity and driver convenience [1-5]. 
Yet, recently there are growing dissenting opinions with regards to those claims from the perspective of sustainable and livable cities. The strongest proponents of two-way streets are from researchers in the humanities and economics, arguing for bidirectional traffic that significantly slows down traffic speed and hence improves the safety of pedestrians and also reinvigorates the businesses along the street [6-11]. On the other hand, contemporary traffic engineers have greater access to modern traffic modelling and simulation tools that allowed study of street configurations with better context and details compared to empirical data [12-17]. Some of them did not find any positive effect in terms of traffic capacity between one-way and two-way streets [16,17], while some others granted that implementing the directionality of traffic would be very context-sensitive and situation dependent $[12,15]$, for example, two-way streets that banned left-turns could be more efficient compared to one-way streets $[13,14]$.

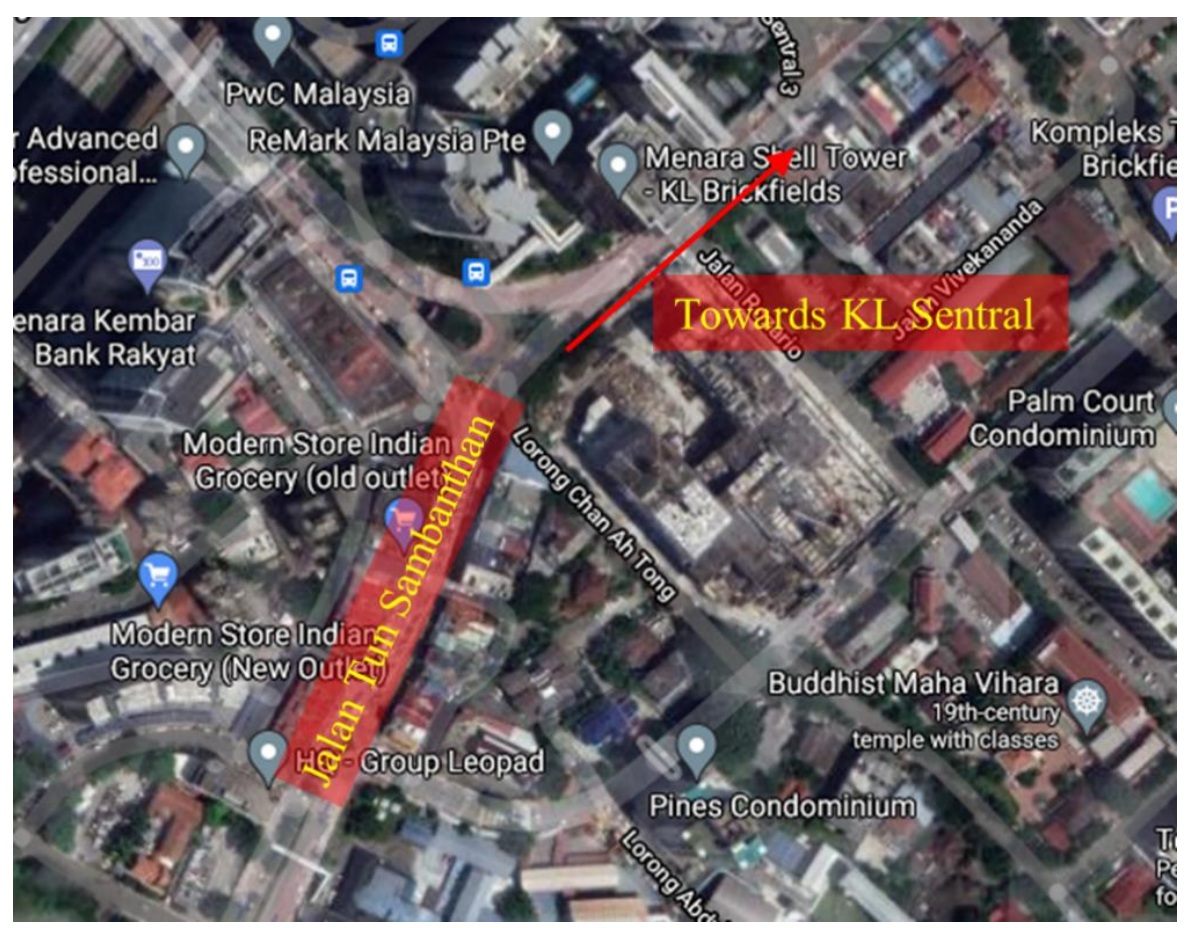

Figure 1. Google Street Maps of Downtown Brickfields, Kuala Lumpur.

In this study, the project team lean towards the contemporary viewpoint that traffic circulation is complex, is locality and context-dependent, and hence must be evaluated on a case-by-case basis. Modern traffic simulation tools were applied to evaluate the efficiency and sustainability of the urban street network in Downtown Brickfields, the heart of Kuala Lumpur city in Malaysia. For context, KL Sentral, which is the central public transportation hub, is located in Brickfields and along with the high population density and being a tourist hotspot, led to the traffic being at a constant congestion. In 2010, The Kuala Lumpur City Hall has implemented a traffic dispersal system to alleviate the congestion, and this has led to Jalan Tun Sambanthan, a street leading towards KL Sentral, being converted into a one-way street that only permits north-east bound traffic (see Figure 1) [18]. Jalan Tun Sambanthan is also located in Little India, which is a bustling economic center. Five years later in 2015, the residents and businesses in the vicinity of Jalan Tun Sambanthan and Little India did not see any positive effects of the street conversion $[19,20]$. While it may be too early to conclude on the outcomes of the street conversion, which may be well alluded to vehicle population growth and induced traffic demand, it may be interesting to conduct a simulation study that is able to study on the network topology alone and preclude the other conflating socioeconomic factors. For this purpose, different traffic scenarios of the Downtown Brickfields urban street network were studied, with Jalan Tun Sambanthan acting as a one-way as well as a two-way street, via microscopic agent-based traffic simulations. 


\section{Materials and Methods}

The traffic network of Downtown Brickfields will be studied using both the macroscopic and microscopic traffic flow model approaches. The macroscopic model allows us to have the general overview of the traffic flow parameters of the network, while the microscopic model is used by the traffic simulation software to generate the traffic scenarios for the flow analysis. For the macroscopic model, we have used the classic Greenshields' traffic flow continuity equation [21], which simply states that the average vehicle speed on a street, $u$, in kilometers per hour $(\mathrm{km} / \mathrm{hr})$, the traffic flow rate, $q$, in vehicles per hour (veh/hr), and the traffic density, $k$, in vehicles per kilometers $(\mathrm{veh} / \mathrm{km})$, is related by

$$
q=k_{j} \cdot u-\left[\frac{k_{j}}{u_{f}}\right] \cdot u^{2}
$$

where, $\mathrm{u}_{\mathrm{f}}$ is the free-flowing traffic speed and $\mathrm{k}_{\mathrm{j}}$ is the traffic density at congestion. At any given time throughout the simulation, the traffic flow rate can be obtained by manually counting the number of vehicles passing through a designated point on the street, while the traffic density can be obtained by counting the number of vehicles that occupies the whole stretch of the street, and then divided by the length of the street. The average vehicle speed can then be calculated from the equation using the obtained values of traffic flow and density.
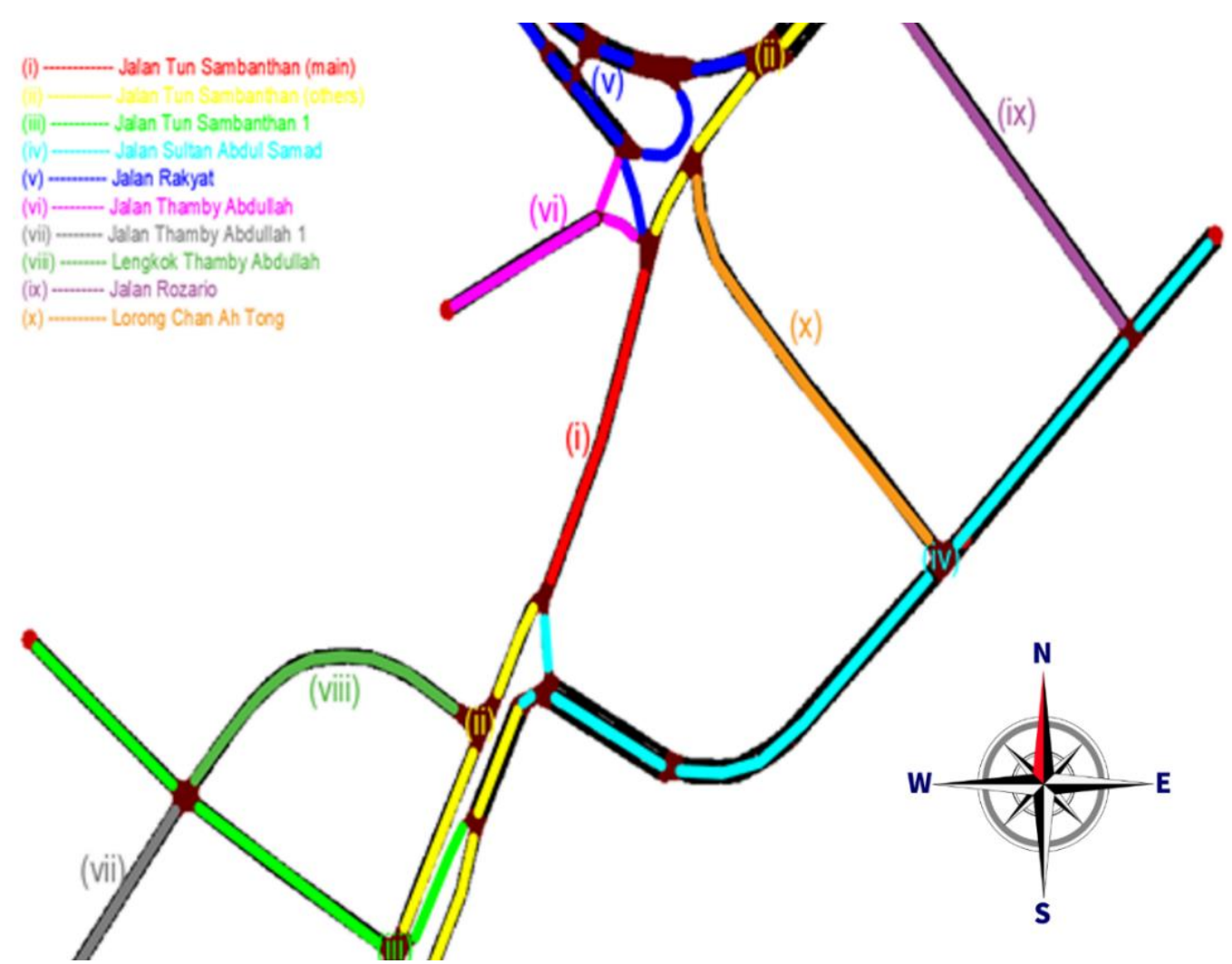

Figure 2. Urban street network of Downtown Brickfields, Kuala Lumpur, imported from OSM.

In this study, the open-source traffic simulation package called Simulation of Urban Mobility (SUMO) was adopted [22]. SUMO is a microscopic, multi-modal traffic simulation software that uses the agent-based model approach, whereby each generated vehicle is modelled explicitly, has an own route, and moves individually through the network. The vehicles' movements are constrained by a modified Krauss car-following model [23]. The traffic network of Downtown Brickfields, as can be seen in Figure 1, can then be imported and subsequently used in simulation using Open Street Map (OSM) Web Wizard, which is a tool installed alongside with SUMO. The imported urban street network of Downtown Brickfields is shown in Figure 2. 


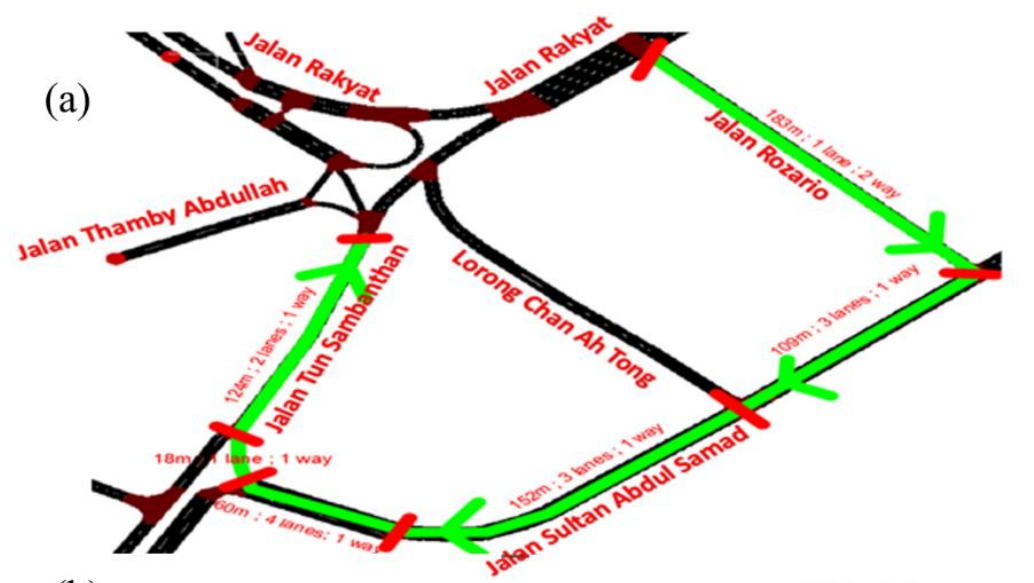

(b)

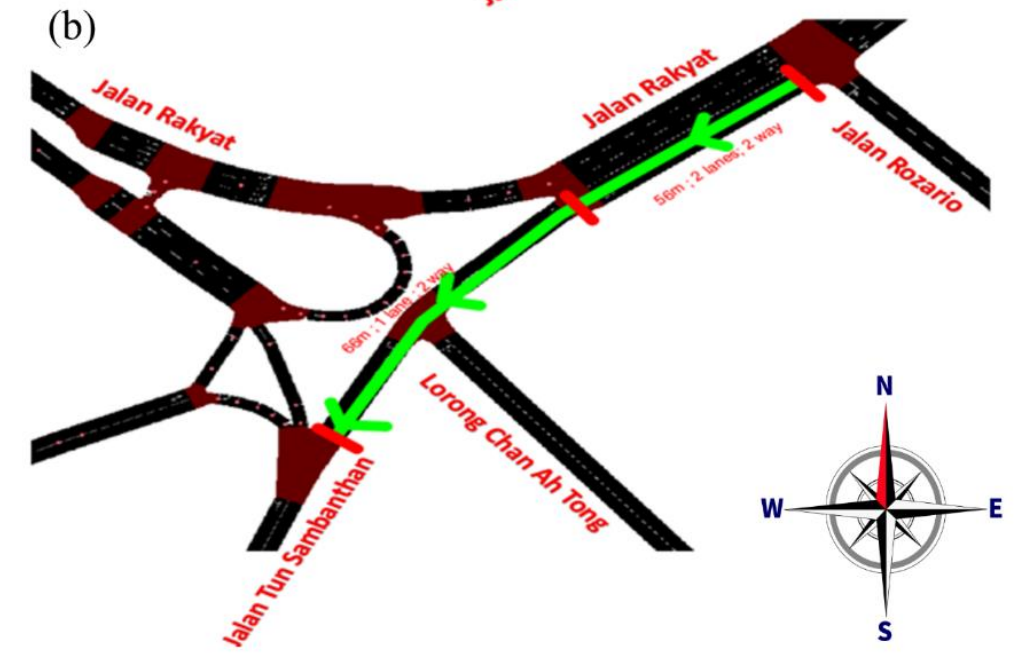

Figure 3. Downtown Brickfields urban street network with Jalan Tun Sambanthan as (a) a oneway street, and (b) a two-way street. The green arrows show the enforced route plan of vehicles generated along Jalan Rakyat.

After the street network is imported, Jalan Tun Sambanthan was modified into a twoway street using netedit, a graphical network editor included in SUMO. Netedit also allows the creation and removal of streets, as well as connection and reconnection of paths at intersections or junctions. To generate trips for vehicles, the randomtrips function of SUMO was used to generate vehicles randomly in the network, which follows the algorithm of the Mersenne Twister [24]. A total of 5000 vehicles will be generated at random positions on the map at the rate of one vehicle per second, and this will form the baseline traffic activity for the whole map. In addition to this, in order to analyze the impact of the street conversion of Jalan Tun Sambanthan on traffic flow, in particular, the south-west bound traffic coming from KL Sentral, a calibrator function is deliberately set up along Jalan Rakyat. This calibrator function generates another 5000 vehicles at the same rate of one vehicle per second, but is also able to enforce a specific route plan for them. For the oneway street simulation, the vehicles generated by the calibrator function is set to traverse a long detour along Jalan Rozario and Jalan Sultan Abdul Samad to reach Jalan Tun Sambanthan, as shown in Figure 3(a), while for the two-way street simulation, the generated vehicles can directly enter Jalan Tun Sambanthan, as shown in Figure 3(b). 
Table 1. Dataset of traffic simulation in one-way and two-way street networks in Downtown Brickfields.

\begin{tabular}{|c|c|c|c|c|c|c|c|c|}
\hline \multicolumn{9}{|c|}{ One-Way Street Network } \\
\hline Elapsed Time (s) & 75 & 145 & 220 & 300 & 370 & 450 & 530 & 600 \\
\hline $\begin{array}{l}\text { Aggregate Traffic Speed } \\
\qquad(\mathbf{k m} / \mathbf{h r})\end{array}$ & 29.54 & 22.44 & 18.00 & 16.30 & 13.36 & 9.61 & 6.73 & 5.76 \\
\hline $\begin{array}{c}\text { Traffic Flow Rate, q } \\
\text { (veh/hr) }\end{array}$ & 517.89 & 1268.3 & 1139.2 & 1280.7 & 993.16 & 602.30 & 541.28 & 400.81 \\
\hline Traffic Density, k (veh/km) & 35.60 & 35.60 & 56.76 & 66.56 & 83.08 & 117.65 & 142.93 & 178.53 \\
\hline \multicolumn{9}{|c|}{ Two-Way Street Network } \\
\hline $\begin{array}{l}\text { Aggregate Traffic Speed } \\
\qquad(\mathrm{km} / \mathrm{hr})\end{array}$ & 27.05 & 22.31 & 16.63 & 12.11 & 8.05 & 5.34 & 3.23 & 3.16 \\
\hline $\begin{array}{c}\text { Traffic Flow Rate, q } \\
\text { (veh/hr) }\end{array}$ & 842.30 & 960.37 & 979.25 & 957.91 & 1065.5 & 1068.6 & 1089.2 & 635.57 \\
\hline Traffic Density, k (veh/km) & 76.50 & 92.90 & 98.36 & 87.43 & 68.31 & 73.77 & 84.70 & 133.88 \\
\hline
\end{tabular}
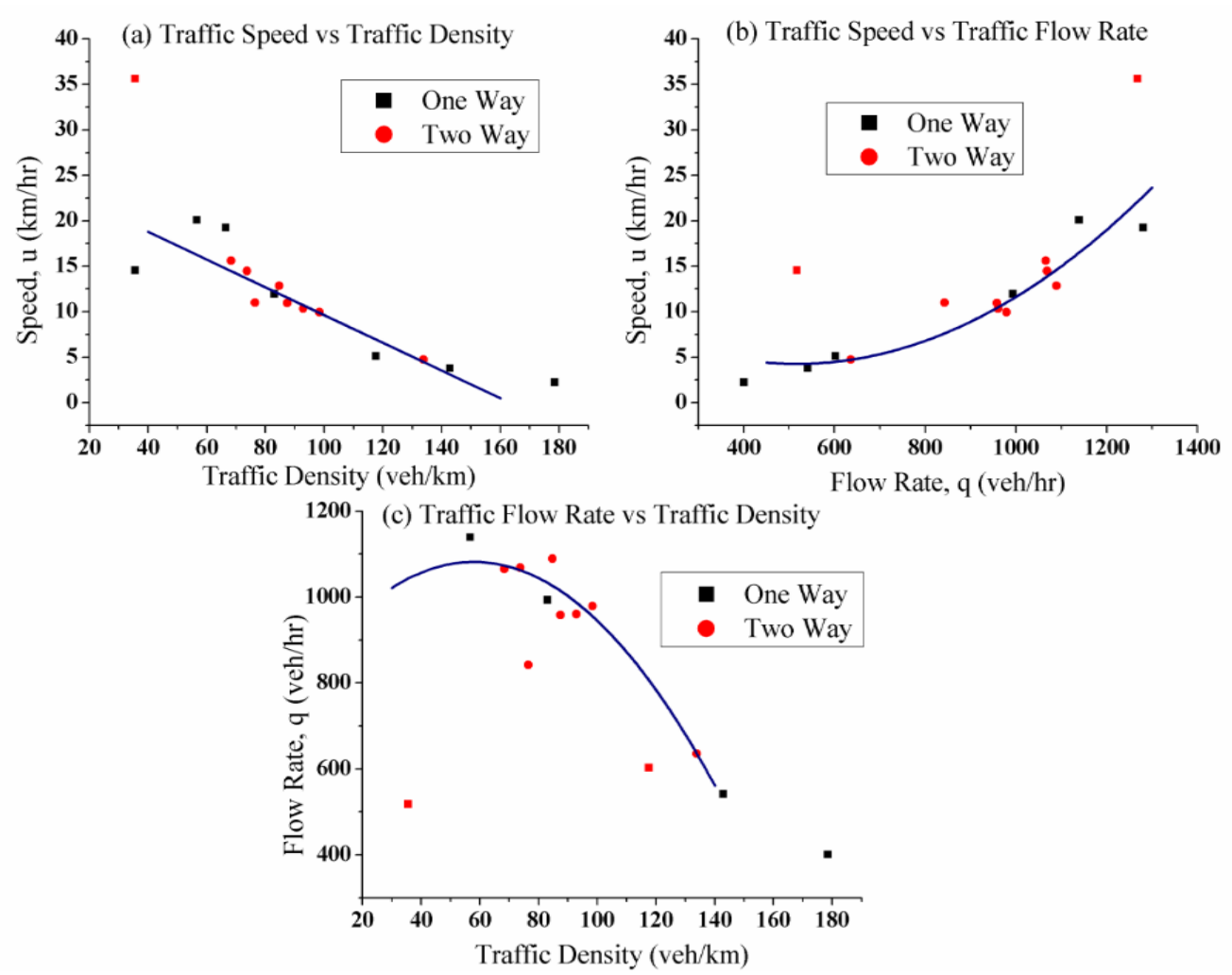

Figure 4. Fundamental diagrams of traffic flow, showing (a) traffic speed vs. traffic density, (b) traffic speed vs. traffic flow rate, and (c) traffic flow rate vs. traffic density. Regression analysis shows that the both one-way and two-way traffic data fit well to the Greenshields' empirical model [21].

\section{Results and Discussion}

Three simulations were performed, each for both one-way street and two-way street traffic. For each simulation, the macroscopic traffic parameters of traffic flow rate and density are obtained by manual counting of vehicles at a given elapsed time. The only quantity that is extracted automatically from SUMO is the Aggregate Traffic Speed of Network, which is aggregated from all the existing vehicles' movement in the map. These traffic parameters are inspected and recorded at different elapsed times as the simulation progressed. The results from all three simulations are combined and the average values are taken, which are tabulated in Table 1. 
In order to verify the validity of the simulations, the time-invariant classic fundamental diagrams of traffic flow, namely the traffic speed-density, traffic speed-flow rate, and traffic flow rate-density relationship diagrams has been constructed, as shown in Figure 4. The data points plotted in these diagrams all originate from Table 1, for both one-way and two-way street networks, and at all points of elapsed time. Regression analysis on these data shows that the curves fit very well to Greenshields' empirical model of traffic flow [21], hence proving a concrete link of the microscopic traffic process giving rise to the macroscopic traffic phenomenon.

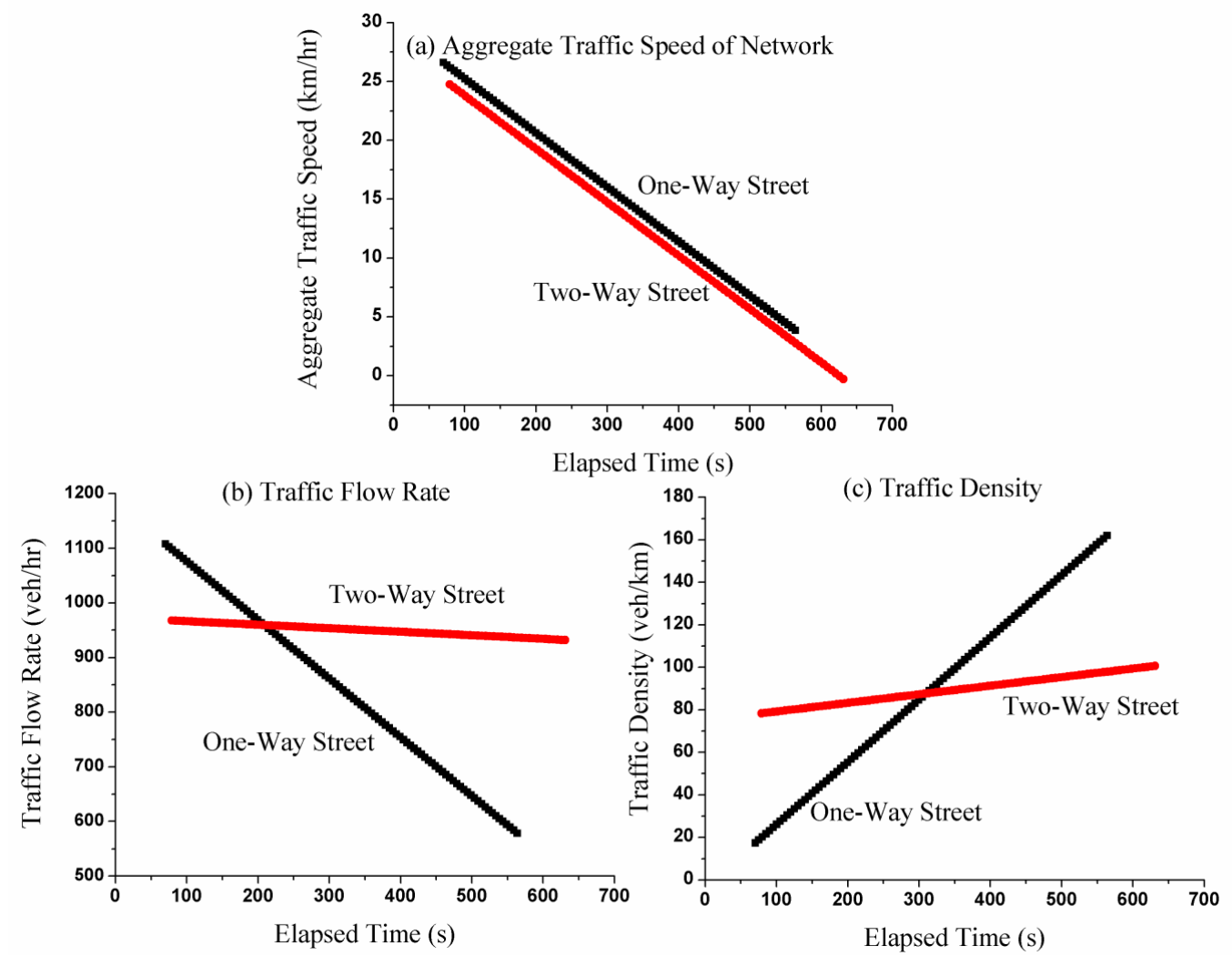

Figure 5. Analysis of traffic situation evolution over time for (a) aggregate traffic speed of the network, (b) traffic flow rate of each route, and (c) traffic density of each route.

Next, performance of one-way and two-way streets by observing the evolution of the macroscopic traffic parameters over the elapsed time of simulation was evaulated. In Figure 5(a) the plot of the aggregate traffic speed shows that there is only marginal improvement of one-way streets compared to two-way streets, but in both cases, the traffic speed decreases over time as traffic congestion builds up. Figures $5(b-c)$ show a better picture of the evolving traffic scenario over time for each specific enforced route plan. For one-way streets, it is evident that the traffic flow rate is initially very high as the traffic density and number of vehicles on the route are low. One-way streets, true to their nature of having high traffic capacity due to longer travel distances, can defer traffic congestion by dispersing traffic to neighboring areas. However, longer travel distances also mean that drivers would also have to take a longer time to arrive at their intended destinations, resulting in accumulation of traffic that leads to congestion. As can be seen from the graphs, as time progresses in the simulation, there is a steep decrease in the traffic flow rate, accompanied by a steep increase in traffic densities. At the 600 -second mark, it would seem that the traffic congestion has become twice as worse compared to two-way streets (traffic flow rate of one-way is halved, and traffic density is twice that of two-way streets). 
Table 2. Traffic clearance time for one-way and two-way street networks.

\begin{tabular}{|c|c|c|c|c|c|c|c|c|}
\hline \multicolumn{9}{|c|}{ One Way Street $(0.646 \mathrm{~km})$} \\
\hline Elapsed Time (s) & 75 & 145 & 220 & 300 & 370 & 450 & 530 & 600 \\
\hline $\begin{array}{l}\text { Aggregate Traffic Speed } \\
\qquad(\mathrm{km} / \mathrm{hr})\end{array}$ & 29.54 & 22.44 & 18.00 & 16.30 & 13.36 & 9.61 & 6.73 & 5.76 \\
\hline Trip Completion Time (s) & 78.7 & 103.6 & 129.2 & 142.7 & 174.1 & 242.0 & 345.5 & 403.75 \\
\hline \multicolumn{9}{|c|}{ Two Way Street $(0.122 \mathrm{~km})$} \\
\hline $\begin{array}{l}\text { Aggregate Traffic Speed } \\
\qquad(\mathrm{km} / \mathrm{hr})\end{array}$ & 27.05 & 22.31 & 16.63 & 12.11 & 8.05 & 5.34 & 3.23 & 3.16 \\
\hline Trip Completion Time (s) & 16.2 & 19.7 & 26.4 & 36.3 & 54.6 & 82.2 & 136.0 & 139.0 \\
\hline Completion Time Ratio & 4.86 & 5.25 & 4.89 & 3.93 & 3.19 & 2.94 & 2.54 & 2.9 \\
\hline
\end{tabular}

In contrast, two-way streets, having smaller traffic capacity, start off with a significantly lower traffic flow rate, as well as a much higher traffic density. Yet, the shorter route plan enabled a higher rate of clearing traffic as drivers can reach their destinations faster. The traffic flow rate and density remain relatively constant as the traffic scenario evolves over time. In Table 2, we have recorded the trip completion time for vehicles travelling in each route at different elapsed time of the simulation. As expected, the one-way street network having a longer travel distance of 0.646 kilometers has a consistently longer travel time, compared to the two-way street network with a shorter travel distance of only 0.122 kilometers. On average, the trip completion time of the one-way street route plan is about four times longer than the two-way street route plan.

\section{Conclusions}

In the simulation analysis of the street configuration in Downtown Brickfields, Kuala Lumpur, it was clearly shown that one-way street networks may not always be more efficient than two-way street networks, but they are dependent on the traffic scenario that evolves over time. One-way streets do allow higher traffic flow rate and lower traffic densities by spreading out the traffic to neighboring streets, and thus perform better at the onset of traffic congestion. But this higher traffic capacity also served as a double-edged sword in prolonging travel times, accumulating traffic which eventually led to congestion. Two-way streets, on the other hand, have a higher clearance rate for traffic and thus has a more stable traffic flow rate and density parameters, notwithstanding the lower initial traffic flow and higher densities. This case study analysis precluded all possible socioeconomic factors like vehicular population growth and induced traffic demand, and hence would give a fair representation to the actual efficiencies caused by changes in the traffic circulation plan alone.

In this sense, the results corroborate well with the anecdotal accounts of residents in Downtown Brickfields, who have complained that the conversion of Jalan Tun Sambanthan into a one-way street did little to alleviate traffic congestion on that street [19], and has instead induced traffic congestion in the neighboring streets, and at worst became a contributing factor to the dwindling community and decay of the local economy [20]. The unsustainable socioeconomic developments of Downtown Brickfields have eerily drawn parallels with the series of works by Riggs in his analysis of street conversions in various cities located in the United States of America [6-8]. This case study may serve as a cautionary tale of porting over traffic systems that may be incompatible to the local context, and reinforces the notion of complexity in sustainable traffic network design that must be reviewed on a case-by-case basis, as well as on a periodic basis to account for changes in traffic scenarios due to urban developments. 


\begin{abstract}
Author Contributions: Conceptualization, Y.H.C. and K.J.A.O.; methodology, Y.H.C.; software, Y.H.C.; validation, Y.H.C. and Q.Y.T.; formal analysis, Y.H.C. and Q.Y.T.; investigation, Y.H.C. and Q.Y.T.; resources, Y.H.C. and M.B.I.R.; data curation, Y.H.C.; writing-original draft preparation, Y.H.C.; writing-review and editing, Y.H.C.; C.W.Y. and K.J.A.O.; visualization, M.A.S.B. and B.V.D.K.; supervision, K.J.A.O.; project administration, K.J.A.O.; funding acquisition, M.A.S.B.; B.V.D.K.; M.B.I.R. and K.J.A.O. All authors have read and agreed to the published version of the manuscript.
\end{abstract}

Funding: This research was funded by the Ministry of Higher Education Malaysia through the Fundamental Research Grant Scheme (FRGS), project number FRGS/1/2019/TK08/XMU/02/1. Support from the Xiamen University Malaysia Research Fund (XMUMRF), grant numbers XMUMRF/2020C5/IENG/0025, XMUMRF/2020-C5/IECE/0014, and XMUMRF/2019-C3/IECE/0003 is also gratefully acknowledged.

Data Availability Statement: All data generated or analyzed during this study are included in this published article.

Conflicts of Interest: The authors declare no conflict of interest.

\title{
References
}

1. Zhang, J.; Zhang, X.; Yang, Y.; Zhou, B. Study on the influence of one-way street optimization design on traffic operation system. Meas. Control 2020, 53, 1107-1115, doi:10.1177/0020294020932366.

2. Stemley, J.J. One-way streets provide superior safety and convenience. ITE J. 1998, 68, 47-50.

3. Karimi, H.; Ghadirifaraz, B.; Shetab Boushehri, S.N.; Hosseininasab, S.-M.M.; Rafiei, N. Reducing traffic congestion and increasing sustainability in special urban areas through one-way traffic reconfiguration. Transportation (Amst). 2021, 1-24, doi:10.1007/s11116-020-10162-4.

4. Salcedo-Sanz, S.; Manjarrés, D.; Pastor-Sánchez, Á.; Del Ser, J.; Portilla-Figueras, J.A.; Gil-López, S. One-way urban traffic reconfiguration using a multi-objective harmony search approach. Expert Syst. Appl. 2013, 40, 3341-3350, doi:10.1016/j.eswa.2012.12.043.

5. American Association of State Highway and Transportation Officials A Policy on Geometric Design of Highways and Streets, 6th Edition; 2011; ISBN 9781560515081.

6. Riggs, W.; Gilderbloom, J. Two-Way Street Conversion: Evidence of Increased Livability in Louisville. J. Plan. Educ. Res. 2016, 36, 105-118, doi:10.1177/0739456X15593147.

7. Riggs, W.; Appleyard, B. The economic impact of one to two-way street conversions: advancing a context-sensitive framework. J. Urban. Int. Res. Placemaking Urban Sustain. 2018, 11, 129-148, doi:10.1080/17549175.2017.1422535.

8. Riggs, W.; Gilderbloom, J.I. “Hans" How multi-lane, one-way street design shapes neighbourhood life: collisions, crime and community. Local Environ. 2017, 22, 917-933, doi:10.1080/13549839.2017.1303666.

9. Wazana, A.; Rynard, V.L.; Raina, P.; Krueger, P.; Chambers, L.W. Are Child Pedestrians at Increased Risk of Injury on One-way Compared to Two-way Streets? Can. J. Public Health 2000, 91, 201, doi:10.1007/BF03404272.

10. Hocherman, I.; Hakkert, A.S.; Bar-Ziv, J. Safety of one-way urban streets. Transp. Res. Rec. Transp. Res. Rec. 1990, $1270,22-27$.

11. Walker, G.W.; Kulash, W.M.; McHugh, B.T. Downtown Streets: Are We Strangling Ourselves in One-Way Networks? In Proceedings of the Transportation Research Circular; 2000; pp. 1-18.

12. Chiu, Y.-C.; Zhou, X.; Hernandez, J. Evaluating Urban Downtown One-Way to Two-Way Street Conversion Using Multiple Resolution Simulation and Assignment Approach. J. Urban Plan. Dev. 2007, 133, 222-232, doi:10.1061/(ASCE)07339488(2007)133:4(222).

13. Gayah, V.; Daganzo, C. Analytical capacity comparison of one-way and two-way signalized street networks. Transp. Res. Rec. 2012, 76-85, doi:10.3141/2301-09.

14. Ortigosa, J.; Gayah, V. V.; Menendez, M. Analysis of one-way and two-way street configurations on urban grid networks. Transp. B Transp. Dyn. 2019, 7, 61-81, doi:10.1080/21680566.2017.1337528.

15. Bindzar, P.; Saderova, J.; Sofranko, M.; Kacmary, P.; Brodny, J.; Tutak, M. A Case Study: Simulation Traffic Model as a Tool to Assess One-Way vs. Two-Way Traffic on Urban Roads around the City Center. Appl. Sci. 2021, Vol. 11, Page 5018 2021, 11, 5018, doi:10.3390/APP11115018.

16. Liu, B.; Mehrara Molan, A.; Pande, A.; Howard, J.; Alexander, S.; Luo, Z. Microscopic Traffic Simulation as a Decision Support System for Road Diet and Tactical Urbanism Strategies. Sustainability 2021, 13, 8076, doi:10.3390/su13148076.

17. Rojo, M. Evaluation of traffic assignment models through simulation. Sustainability 2020, 12, 5536, doi:10.3390/su12145536.

18. Changes to traffic system in Brickfields Available online: https://www.thestar.com.my/news/community/2010/07/30/changesto-traffic-system-in-brickfields (accessed on Aug 17, 2021).

19. Mixed reaction to Little India upgrade Available online: https://www.thestar.com.my/metro/focus/2015/01/08/mixed-reactionto-little-india-upgrade (accessed on Aug 17, 2021).

20. Brewing identity crisis seen in Brickfields Available online: https://www.edgeprop.my/content/brewing-identity-crisis-seenbrickfields (accessed on Aug 25, 2021).

21. Greenshields, B.D.; Channing, W.S.; Miller, H.H. A study of traffic capacity. In Proceedings of the 14 Annual Meeting of the Highway Research Board Proceedings; 1935; Vol. 1935, pp. 448-477. 
22. Lopez, P.A.; Wiessner, E.; Behrisch, M.; Bieker-Walz, L.; Erdmann, J.; Flotterod, Y.-P.; Hilbrich, R.; Lucken, L.; Rummel, J.; Wagner, P. Microscopic Traffic Simulation using SUMO. In Proceedings of the 2018 21st International Conference on Intelligent Transportation Systems (ITSC); IEEE, 2018; pp. 2575-2582.

23. Krauss, S.; Wagner, P.; Gawron, C. Metastable states in a microscopic model of traffic flow. Phys. Rev. E 1997, 55, 5597-5602, doi:10.1103/PhysRevE.55.5597.

24. Matsumoto, M.; Nishimura, T. Mersenne twister: a 623-dimensionally equidistributed uniform pseudo-random number generator. ACM Trans. Model. Comput. Simul. 1998, 8, 3-30, doi:10.1145/272991.272995. 